\title{
Supplementing nursery pig feed with seaweed extracts increases final body weight of pigs
}

\author{
Álvaro R. Ruiz ${ }^{\text {** }}$ Paula Gadicke ${ }^{\mathrm{a}}$, Stephanie M. Andrades ${ }^{\mathrm{a}}$, Reinaldo Cubillos ${ }^{\mathrm{b}}$
}

\begin{abstract}
Probiotics have been used as an alternative method to antibiotic treatment. In this study, we evaluated the effect of seaweed extracts, commercially named OceanFeed Swine ${ }^{\circledR}$ (OFS), on body weight, average daily weight gain (ADG) and feed efficiency (FE) in nursery and fattening pigs of terminal lines. The study was conducted with 1809 piglets from weaning age until the end of the fattening phase on a commercial farm, divided into two groups (control and OFS; 905 and 904 pigs, respectively). Three replicates were made during the 6 weeks of production. Food was elaborated in the same productive unit and was given to the animals in the form of flour. OceanFeed Swine ${ }^{\circledR}(5 \mathrm{~g} / \mathrm{kg}$ of diet) was added to the diet of the OFS groups during the nursery period, from 21 to 55 days of age. The faecal microbial population was evaluated at 35 and 60 days of life. In this paper, we observed a positive effect of administering OceanFeed Swine ${ }^{\circledR}$ on the production parameters analysed in the fattening phase, showing an improvement of $26 \mathrm{~g}$ in ADG and FE of 0.07. It can be concluded that the use of OceanFeed Swine ${ }^{\circledR}$ in the diets of the piglets, aged between 21 to 55 days old, improves FE (Control 2.36, OFS 2.29) and ADG (control $0.798 \mathrm{~kg}$, OFS $0.824 \mathrm{~kg}$ ). Moreover, its use exhibited an increase in the slaughter weight, a reduction of $E$ coli $\mathrm{CFU}$, and an increase in Lactobacillus sp. in fattening animals. All these improvements have a major positive economic impact per pig at time of slaughter.

Key words: seaweed extracts, nursery, production parameters.
\end{abstract}

\section{INTRODUCTION}

One of the main objectives within the porcine industry is that animals should achieve optimal production parameters, such as low mortality rates, higher average daily weight gain and greater feed efficiency (Gómez et al 1999, Gómez et al 2009). Multiple factors affect these parameters, with one of these being the quality of the food that animals consume on the farm. Apart from this, it is important for pigs to have a digestive system in optimal condition to maximise benefits from delivered nutrients (Leonard et al 2015, Gómez et al 2009), thus attempting to minimise the negative sanitary effects in animals, caused mainly by enterobacteriaceae, such as E. Coli, among others (Reilly et al 2008).

In recent decades, probiotic products have been used as a potent alternative method to the excessive use of antibiotics (Kyriakis et al 1999, Schareka et al 2005). However, supplementation with prebiotics based on seaweed, has only recently gained attention. This is due to multiple benefits (Makkar et al 2016), such as an increase in nutrient digestibility as well as improvements in the intestinal physiology and immunity of animals (Bahar et al 2012, Jha and Berrocoso 2016). Seaweed are rich in non-digestible polysaccharides such as laminarin, fucoidan and alginic acid (Zvyagintseva et al 2003, Rajauria et al 2016), which are a possible source of soluble fibers that

Accepted: 15.03.2018.

aDepartamento de Patología y Medicina Preventiva, Facultad de Ciencias Veterinarias, Universidad de Concepción, Chillán, Chile.

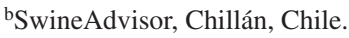

*Corresponding author: Vicente Méndez Avenue 595, Chillán, Chile; aruiz@udec.cl can provide a dietetic resource to improve intestinal health and potentially reduce intestinal pathogens (Gardiner et al 2008). These natural products can be used in nursery and fattening diets because they are a rich source of carbohydrates. Furthermore, they also decrease the amount of lactose used in starter diets for piglets (Gahan et al 2009). These prebiotics are ideal for a change to piglets' solid diets, because they cause the intestinal flora to adjust. Therefore, the damage caused by enterobacteriaceae is reduced, which typically increases in this phase, improving animal growth and health due to certain antimicrobial properties of the prebiotics (Lynch et al 2010).

This study aimed to evaluate the effect of seaweed extracts $\left(\right.$ OceanFeed Swine $\left.{ }^{\circledR}\right)$ on body weight, average daily weight gain (ADG) and feed efficiency (FE) in nursery and fattening pigs of terminal lines.

\section{MATERIAL AND METHODS}

\section{TESTING LOCATION}

This study was performed in an intensive swine production system, with a closed-loop system and a stock of 600 sows, located in the Bio Bio Region, Chile.

\section{EXPERIMENTAL UNITS AND MANAGEMENT}

This study was carried out beginning at weaning age, at 21 days of life, until the end of fattening phase, aged around 160 days. The experimental unit was a group of weaning pigs of one week in the production system, which were located in nursery rooms with eight pens of 40-45 pigs each, until 65 days of age approximately, and a fattening room, located in another building, with a capacity of 800 pigs approximately, until 160 days of age approximately. 
Feeding was carried out manually in a hopper feeder, so that pigs could have ad libitum feeding. All diets coverer the nutrient requirements of the different phases according to the NRC 2012 requirements. The animals were provided with ad libitum drinking water by an automatic nippler. The floors were $100 \%$ slotted plastic floor both in the nursery and fattening period.

\section{TREATMENTS USED}

In total, 1809 animals were used. Pigs were divided into a control group with 905 animals and a OFS (Ocean Feed Swine) group with 904 animals. Three replicates were made in a period of 6 weeks of production, alternating control and OFS groups. The food was elaborated in the same production unit and was given to the animals in the form of flour. OceanFeed Swine ${ }^{\circledR}$ (Milltown, Tuam, Co Galway, Ireland) was added into the diet of the OFS groups during the nursery period, in a proportion of 5 kilograms per ton of feed $(5 \mathrm{~g} / \mathrm{kg})$. Diets were delivered from 21 to 55 days of age, with this being the only difference in the feeding of the two study groups. The processing of control and OFS rations was done simultaneously for both experimental groups, in order to ensure the use of the same batches of raw material. Piglet monitoring started at the beginning of weaning (21 days) and ended at the moment of slaughter (160 days). During these periods, feed consumption was registered daily, identifying the type of food and the amount of kilos consumed. The animals were weighed from both groups at 21, 60, and 160 days of age. Then, the average daily weight gain (ADG) was calculated as the difference between final and initial body weight of each period divided by the length of the period in days. Feed efficiency (FE) was also calculated, as the food consumption per pig during the period divided by the difference between the final and initial weight of each period.

A food sample was taken from diet phases 1,2 and 3 in both experimental groups from each replicate at the moment these were carried out, for their proximate analysis of nutrients using the Weende technique. In total, 18 samples were taken during this study.

At 35 and 60 days of age, six faecal samples were randomly taken from pens and pigs in each replicateto be analysed individually (with a total of 18 OFS samples and 18 controls). The faecal samples were used to quantify intestinal flora through the plate counting of Colony forming units (CFU) of faecal coliforms ( $E$ coli). Ten $g$ of faecal sample were inoculated in $90 \mathrm{~mL}$ of Butterfield buffer and serial dilutions of $-1,-2,-3$ and -4 were carried out. One $\mathrm{mL}$ was sowed from each dilution in Chromocult coliform agar (Merk) for 24 hours at $37^{\circ} \mathrm{C}$. For the Lactobacillus sp. count, $10 \mathrm{~g}$ of each sample were weighed and inoculated in $90 \mathrm{~mL}$ of Butterfield buffer. From these, dilutions of -2 and -3 were prepared. Then, $1 \mathrm{~mL}$ from each dilution was taken and sowed, in duplicate, in MRS agar (Merck) and incubated for 48 hours at $37{ }^{\circ} \mathrm{C}$, in microaerophilic conditions with $5 \% \mathrm{CO}_{2}$. The colonies that were obtained were selected based on morphology observation, Gram's stain and a catalase test.

\section{STATISTICAL ANALYSIS}

The statistical analysis was carried out primarily through descriptive statistics for each step of the study including: number of animals, duration of the stage, weight at the end of it, ADG, FE (mean and Std. Err.). Shapiro-Wilk's normality test and Bartlett's homoscedasticity test were performed, both with $95 \%$ confidence, to check the assumptions of the inferential test. The differences between the groups' average values were analysed through multivariate analysis of variance (MANOVA), which is an analysis of variance with several dependent variables. Both the effects of the testing factor (control and OFS) and their interactions were considered, using a $95 \%$ confidence interval. The dependent variables were average daily consumption of food, ADG and FE. For the analysis of treatments regarding weight at moment of slaughter (160 days), as dependent variable, a multiple regression analysis was performed. Moreover, a principal component analysis was done (InfoStat 2014) to identify multivariate connections between the quantitative variables measured in the testing (Dohoo 2009).

\section{RESULTS}

As shown in table 1, the number of animals used in each treatment was similar, as well as the weaning weight. Statistically significant differences were not exhibited between the OFS group and control group $(P>0.05)$ and they had normal distribution. However, the effects between replicates were considered in the statistical analysis for control purposes. The consumption differences of each feeding phase from each treatment were not significant $(P>0.05)$ and were used to calculate ADG and FE as shown in table 1.

When analysing the ADG of nursery (table 1), the control group showed a better performance $(0.401 \mathrm{~kg})$ than the OFS group $(0.380 \mathrm{~kg})(P<0.05)$, with a difference of $0.02 \mathrm{~kg}$ in favour of the first group.

In the nursery phase, FE in the OFS group was lower (1.88) than the control group (1.95), $P<0.05$, with a difference of $70 \mathrm{~g}$ in favour of the first group.

The ADG analysis of the fattening phase found the OFS group was different $(P<0.05)$, showing a better performance $(0.824 \mathrm{~kg})$ versus the control group $(0.798 \mathrm{~kg})$, as it is shown in table 1 , with a difference of $0.026 \mathrm{~kg}$ in favour of the first group.

In the fattening phase, the FE in the OFS group was better (2.29) than the control group (2.36), $P<0.05$, with a difference of $70 \mathrm{~g}$ in favour of the first group.

The principal component analysis indicated that, in its first component, the variables of fattening ADG and the slaughter weight were grouped, remaining the centroid of 
Table 1. Summary of the production parameters during nursery and fattening phases of OFS group (OceanFeed Swine $\left.{ }^{\circledR}\right)$ and control groups.

\begin{tabular}{lcc}
\hline & Control group (Std. Err.) & OFS group (SE) \\
\hline \# nursery pigs & $905^{\mathrm{a}}$ & $904^{\mathrm{a}}$ \\
Weaning weight $(\mathrm{kg})$ & $5.93^{\mathrm{a}}(0.01)$ & $5.98^{\mathrm{a}}(0.02)$ \\
Nursery weight end $(\mathrm{kg})$ & $31.56^{\mathrm{a}}(0.12)$ & $30.73^{\mathrm{b}}(0.12)$ \\
Nursery feed consumption $(\mathrm{kg})$ & $49.40^{\mathrm{a}}(0.18)$ & $46.63^{\mathrm{a}}(0.17)$ \\
Nursery time (days) & $65.33^{\mathrm{a}}(0.13)$ & $65.33^{\mathrm{a}}(0.13)$ \\
Nursery ADG (kg) & $0.401^{\mathrm{a}}(0.00)$ & $0.380^{\mathrm{b}}(0.001)$ \\
Nursery FE & $1.95^{\mathrm{a}}(0.01)$ & $1.88^{\mathrm{b}}(0.01)$ \\
\# fattening pigs & 886 & 883 \\
Slaughter weight $(\mathrm{kg})$ & $90.97^{\mathrm{a}}(0.47)$ & $92.38^{\mathrm{b}}(0.47)$ \\
Fattening feed consumption $(\mathrm{kg})$ & $131.93^{\mathrm{a}}(0.53)$ & $131.87^{\mathrm{a}}(0.75)$ \\
Fattening time (days) & $74^{\mathrm{a}}(0.09)$ & $74^{\mathrm{a}}(0.09)$ \\
Fattening ADG (kg) & $0.798^{\mathrm{a}}(0.00)$ & $0.824^{\mathrm{b}}(0.00)$ \\
Fattening FE & $2.36^{\mathrm{a}}(0.02)$ & $2.29^{\mathrm{b}}(0.07)$ \\
FE study period & $2.15^{\mathrm{a}}(0.01)$ & $2.08^{\mathrm{b}}(0.01)$ \\
ADG (kg) study period & $0.590^{\mathrm{a}}(0.02)$ & $0.600^{\mathrm{b}}(0.02)$ \\
\hline
\end{tabular}

a, b: Different letters in superscript within each parameter indicate statistically significant differences $(P<0.05)$.

SE: Standard error.

Table 2. Multiple regression analysis for the influence of replicates and treatments on weight at time of slaughter (160 days).

\begin{tabular}{lccccc}
\hline Variable & Coefficient & SE & Lower limit (95\%) & Upper limit (95\%) & $P$ value \\
\hline \multicolumn{7}{c}{ Dependent variable slaughter weight, $\mathrm{N}=1718, \mathrm{R}^{2}=0.02, \mathrm{R}^{2} \mathrm{Aj}=0.01$} \\
\hline Const & 79.00 & 2.98 & 73.15 & 84.84 & $<0.0001$ \\
Nursery weight & 0.41 & 0.09 & 0.23 & 0.58 & $<0.0001$ \\
OFS & -1.62 & 0.67 & -2.94 & -0.30 & 0.0163 \\
Replicate 1 & 1.30 & 0.85 & -0.37 & 2.97 & 0.1272 \\
Replicate 2 & 0.73 & 0.85 & -0.95 & 2.40 & 0.3948 \\
\hline
\end{tabular}

SE: Standard error.

Table 3. Average results of Escherichia coli (E. coli) and Lactobacillus sp. CFU count analysis of faeces samples taken from 35 and 60 days of age, classified by control and OFS group.

\begin{tabular}{lccccc}
\hline & \multicolumn{2}{c}{ Control } & & \multicolumn{2}{c}{ OFS } \\
\cline { 2 - 3 } \cline { 5 - 6 } & Lactobacillus sp. & E. coli & & Lactobacillus sp. & E. coli \\
\hline Average at 35 days & $31^{\mathrm{a}}$ & $1,214,667^{\mathrm{a}}$ & & $11^{\mathrm{a}}$ & $1,648,555^{\mathrm{a}}$ \\
Average at 60 days & $4,868^{\mathrm{a}}$ & $1,422,178^{\mathrm{a}}$ & & $5,701^{\mathrm{a}}$ & $88,678^{\mathrm{a}}$ \\
\hline
\end{tabular}

${ }^{a}$ Different letters in superscript rows within each parameter indicate statistically significant differences $(P<0.05)$.

the treatment observations towards the same quadrant. On the other hand, the second component is identified with the fattening FE and more weakly, with the nursery weight and the centroid of the control observations.

To analyse the treatment's influences on the final slaughter weight of pigs, a multiple regression analysis was performed (table 2). The nursery weight and the treatment group were significant for the slaughter weight $(P<0.05)$.

A MANOVA model was carried out for slaughter weight, in which a significant difference was found $(P<0.05)$ for the OFS group. Predictions for the slaughter weight were done with a 95\% confidence interval level for the group factor (control and OFS), which can make the estimates of slaughter weight adjust to the fattening phase. This would take the effect of the replicates into account, exhibiting a better performance for the OFS group $(92.38 \mathrm{~kg})$ than the control group $(90.97 \mathrm{~kg})$. Consequently, we can affirm that the OFS group performs statistically better $(P<0.05)$ when adjusting all the analysed variables in the fattening phase.

The microbiological results of the CFU from coliforms and Lactobacillus sp. at 35 days of life are summarised in table 3. The statistical analysis shows that there is no 
significant difference for Lactobacillus sp. and E. coli CFU among the control and treatment groups $(P>0.05)$. However, it does exhibit a tendency to have a greater number of CFU for both Lactobacillus sp. and E. coli in the control group.

The microbiological results of the coliforms and Lactobacillus sp. CFU at 60 days of life are summarised in table 3, where a larger amount of Lactobacillus sp. is observed in the OFS group than the control group. Meanwhile, the CFU of coliforms were greater in the control group than the OFS group; however, the differences were not statistically significant $(P>0.05)$. Although the values are not significantly different, probably due to lack of statistical power, we observed a tendency in favor of the OFS groups, with an increase in Lactobacillus sp. UFC and a decrease in the $E$. coli number.

The proximate nutrients analysis showed that there were no significant differences between humidity, proteins, ashes and fibers and nitrogen-free extract in the nutritional compositions of the feeding phase among both experimental groups (data not shown).

\section{DISCUSSION}

The purpose of the study was to investigate the effect of supplementing feed with a commercial product (OceanFeed Swine ${ }^{\circledR}$ ) based on seaweed extracts on production parameters in the nursery and fattening phases. In parallel, the faecal macrobiotic population was evaluated in both periods. The initial condition of animals for the study was validated due to the fact that the initial weights of animals among the experimental groups were not statistically different $(P>0.05)$.

The ADG results in the nursery phase show a better performance for the control group. These results are not consistent with Sweeney et al (2011), whose results did not exhibit significant differences between the groups, or Walsh et al (2012) who identified a positive effect with seaweed extract supplementation on piglet weight. These differences may be due to the fact that the seaweed extracts or proportions used in these different studies were not the same, or the seaweed extracts used in this study may have had an effect on the palatability. In contrast, the use of nutrients in the diet was better in this study, because the FE was lower for the OFS group, but reduction in the feed intake was observed. Additionally, the FE prediction was also lower for the OFS group.

In Sweeney et al (2011), the animals had been challenged with an enteric pathogen. Nonetheless, other studies such as Leonard et al (2011) have shown that seaweed extract supplementation during lactation and post weaning improves the digestive tract quality; this may be the reason that animals present FE improvements.

During the fattening phase, the ADG of the OFS group animals exhibited better results than the control group. This result contradicts the results of Gardiner et al (2008), where the ADG of the fattening pigs is reduced or without effects when adding different percentages of alga to the diet, which were different from those used in the present study. Additionally, in Gardiner et al (2008) only the last 60 days of the fattening phase were supplemented. In contrast with this study, Gardiner et al (2008) did not observe an effect on the consumption or the FE.

On the other hand, the FE during the fattening phase was lower in the OFS group. This difference is statistically significant. This differs from the results obtained in Gardiner et al (2008), who did not find an effect on FE. Nonetheless, they used a similar product in a different production stage and for a different time of application. The better performance of FE in the fattening phase, in the present study, may be associated with the early supplementation with seaweed extract and its positive effect on animal intestinal health, and thereby a better absorption capacity of nutrients in later phases of life, as stated by Burrin (2010).

The CFU results from the faeces samples did not show a clear effect for the use of OceanFeed Swine ${ }^{\circledR}$ on the number of Lactobacillus sp., unlike the $E$. coli CFU recount during the first 35 days of life, which is likely due to the animals just having started the diet supplementation. A similar study conducted by O'Doherty et al (2010) showed a favorable effect of seaweed extract administration at 60 days of life, when it was administered between 25 and 50 days of life, coinciding with the results observed in the present study. In the total period, we observed that animals supplemented with OceanFeed Swine ${ }^{\circledR}$ have, on average, a better concentration of lactobacillus and a lower amount of $E$ coli UFC than the animals who did not receive this supplementation. These results are also similar to the ones obtained by Walsh et al (2014). Moreover, a favourable effect has also been observed when supplementing feed of pre farrow sows with seaweed extracts, showing a better production performance for the post weaning piglets (McDonnell et al 2010). This better performance may be attributed to better intestinal flora, which was demonstrated in Gardiner et al (2008), who worked with Ascophyllum nodosum extract in fattening animals.

In our study, a positive effect of seaweed extract (OceanFeed Swine ${ }^{\circledR}$ ) administration was observed on the production parameters analysed in the fattening phase. This is similar to the results demonstrated by Turner et al (2002) and Gardiner et al (2008), when this type of product is administered close to the weaning age, providing a longer period of time for the digestive system to improve the animals' physiological efficiency in the following production periods.

The effect on the production parameters (FE and ADG) of the addition of OceanFeed Swine ${ }^{\circledR}$ in nursery diets could have an important positive economic impact in the nursery and fattening phase, but this is associated with the cost of the supplement and the price of the pork meat. 
Based on the results of this study, it is important for future research to create a repeated-measuring design. This design should also allow us to evaluate the effect of the treatment on different categories of weight at birth and weaning age, because it was not possible to do so in the present study.

It can be concluded that the use of OceanFeed Swine ${ }^{\circledR}$ $(5 \mathrm{~kg} / \mathrm{ton})$ in diets of piglets between 21 and 55 days improves the FE in the nursery and fattening phases and the ADG only in the fattening phase. Moreover, the use of OceanFeed Swine ${ }^{\circledR}(5 \mathrm{~kg} / \mathrm{ton})$ showed an increase in the slaughter weight, an apparent reduction of $E$ coli $\mathrm{CFU}$ and an increase in the Lactobacillus sp. CFU in fattening animals.

\section{REFERENCES}

Angell A, Angell S, Nys R, Paul N. 2016. Seaweed as a protein source for mono-gastric livestock. Trends Food Sci Tech 54, 74-84.

Bahar B, O'Doherty JV, Hayes M, Sweeney T. 2012. Extracts of brown seaweeds can attenuate the bacterial lipopolysaccharide-induced pro-inflammatory response in the porcine colon ex vivo. $J$ Anim Sci $90,46-48$.

Burrin D. 2010. Role of nutrition and intestinal adaptation in weanling pig health. Proceedings of the 21th IPVS Congress, Vancouver, Canada, Pp 11-12.

Cofrades S, López-López I, Ruiz-Capillas C, Triki M, Jiménez-Colmenero F. 2011. Quality characteristics of low-salt restructured poultry with microbial transglutaminase and seaweed. Meat Sci 87, 373-380.

Dohoo I, Martin W, Stryhn, H. 2009. Veterinary Epidemiologic Research. $2^{\text {nd }}$ ed. VER Inc., Charlottetown, Canada.

InfoStat. 2014. InfoStat version 2014 Stata 12 SE. Grupo InfoStat FCA, Universidad Nacional de Córdoba, Argentina.

Gahan D, Lynch M, Callan J, O’Sullivan J, O’Doherty J. 2009. Performance of weanling piglets offered low-, medium- or high-lactose diets supplemented with a seaweed extract from Laminaria spp. J Anim Sci 3, 24-31.

Gardiner G, Campbell A, O’Doherty J, Pierce E, Lynch P, et al. 2008. Effect of Ascophyllum nodosum extract on growth performance, digestibility, carcass characteristics and selected intestinal microflora populations of grower-finisher pigs. Anim Feed Sci Technol $141,259-273$

Gómez M, Segura-Correa J, Rodríguez-Buenfil J. 1999. Efecto de año, bimestre y número de parto de la cerda en el tamaño y peso de la camada al nacer y al destete en una granja comercial. Rev Biomed $10,23-28$

Gómez B, Ortega R, Becerril J. 2009. Factores que contribuyen en la variación del peso de la camada al nacimiento y el número de lechones destetados de líneas y cruces maternos porcinos. Revista Computadorizada de Producción Porcina 16, 239-245.

Hernández A, Romero A, González-Stegmaier R, Dantagnana P. 2016. The effects of supplemented diets with a phytopharmaceutical preparation from herbal and macroalgal origin on disease resistance in rainbow trout against Piscirickettsia salmonis. J Aquaculture 454, 109-117.

Jha R, Berrocoso J. 2016. Dietary fiber and protein fermentation in the intestine of swine and their interactive effects on gut health and on the environment: A review. Anim Feed Sci Technol 212 $18-26$.

Kyriakis S, Ttsiloyiannis V, Vlemmas J, Sarris K, Tsinas A, et al. 1999. The effect of probiotic LSP 122 on the control of post-weaning diarrhoea syndrome of piglets. Res Vet Sci 67, 223-228.

Leonard S, Sweeney T, Bahar B, O'Doherty J. 2015. Effect of maternal seaweed extract supplementation on suckling piglet growth, humoral immunity, selected microflora, and immune response after an ex vivo lipopolysaccharide challenge. J Anim Sci 90, 505-514.

Lynch M, Sweeney T, Callan J, O’Sullivan J, O’Doherty J. 2010. The effect of dietary Laminaria-derived laminarin and fucoidan on nutrient digestibility, nitrogen utilisation, intestinal microflora and volatile fatty acid concentration in pigs. $J$ Sci Food Agric 90, 3.

Makkar H, Tranb G, Heuzé V, Giger-Reverdinc S, Lessiree M, et al. 2016. Seaweeds for livestock diets: A review. Anim Feed Sci Technol 212, 1-17.

McDonnell P, Figat S, O’Doherty J. 2010. The effect of dietary laminarin and fucoidan in the diet of the weanling piglet on performance, selected faecal microbial populations and volatile fatty acid concentrations. Animal 4, 579-585.

O'Doherty J, Dillon S, Figat S, Callan J, Sweeney T. 2010. The effects of lactose inclusion and seaweed extract derived from Laminaria spp. on performance, digestibility of diet components and microbial populations in newly weaned pigs. Anim Feed Sci Technol 157, 173-180.

Rajauria G, Draper J, McDonnell M, O'Doherty J. 2016. Effect of dietary seaweed extracts, galactooligosaccharide and vitamin $\mathrm{E}$ supplementation on meat quality parameters in finisher pigs. Innov Food Sci Emerg Technol 37, 269-275.

Reilly P, O'Doherty J, Pierce K, Callan J, O'Sullivan J, et al. 2008. The effects of seaweed extract inclusion on gut morphology, selected intestinal microbiota, nutrient digestibility, volatile fatty acid concentrations and the immune status of the weaned pig. Animal $2,1465-1473$.

Schareka L, Gutha J, Reiterb K, Weyrauchb K, Tarasc D, et al. 2005. Influence of a probiotic Enterococcus faecium strain on development of the immune system of sows and piglets. Vet Immunol Immunop $105,151-161$

Sweeney T, Dillon S, Fanning J, Eganb J, O'Shea C, et al. 2011. Evaluation of seaweed-derived polysaccharides on indices of gastrointestinal fermentation and selected populations of microbiota in newly weaned pigs challenged with Salmonella Typhimurium. Anim Feed Sci Technol 165, 85-94.

Sweeney T, Mereditha H, Ryana M, Gatha V, Thornton K, et al. 2016. Effects of Ascophyllum nodosum supplementation on Campylobacter jejuni colonisation, performance and gut health following an experimental challenge in 10 day old chicks. Innov Food Sci Emerg Technol 37, 247-252.

Turner J, Dritz S, Higgins J, Minton J. 2002. Effects of Ascophyllum nodosum extract on growth performance and immune function of young pigs challenged with Salmonella typhimurium. J Anim Sci 80, 1947-1953.

Walsh A, Sweeney T, O'Shea C, Doyle D, O'Doherty JV. 2012. Effect of supplementing different ratios of laminarin and fucoidan in the diet of the weanling piglet on performance, nutrient digestibility, and fecal scoring. J Anim Sci 90, 215-217.

Zvyagintseva T, Shevchenko N, Chizhov A, Krupnova T, Sundukova E, et al. 2003. Water-soluble polysaccharides of some far-eastern brown seaweeds. Distribution, structure, and their dependence on the developmental conditions. J Exp Mar Biol Ecol 294, 1-13. 
